\title{
Use of Complementary and Alternative Medicine in Siblings of Pediatric Cancer Patients in Germany. A Population-Based Survey
}

\author{
Sven Gottschling ${ }^{1 *}$, Sascha Meyer ${ }^{2}$, Alfred Längler ${ }^{3,4}$, Friedrich Ebinger ${ }^{5,6}$, Patric Bialas ${ }^{7}$, \\ Benjamin Gronwald1 \\ ${ }^{1}$ Centre of Palliative Care and Pediatric Pain, Saarland University, Homburg, Germany \\ 'University Children's Hospital, Department of Neonatology and Pediatric Intensive Care Medicine, Saarland \\ University, Homburg; Germany \\ ${ }^{3}$ Gemeinschaftskrankenhaus Herdecke, Department of integrative Pediatric and Adolescent Medicine, \\ Herdecke, Germany \\ ${ }^{4}$ Witten/Herdecke University, Faculty of Health, Center for integrative Medicine, Witten, Germany \\ ${ }^{5}$ St. Vincenz-Krankenhaus Paderborn, Department of Pediatrics, Paderborn, Germany \\ ${ }^{6}$ University Children's Hospital, Heidelberg, Germany \\ ${ }^{7}$ Department of Anaesthesiology, Intensive Care and Pain Medicine, Saarland University Hospital, Homburg, \\ Germany \\ Email: * sven.gottschling@uks.eu
}

Received 14 February 2014; revised 8 March 2014; accepted 15 March 2014

Copyright (C) 2014 by authors and Scientific Research Publishing Inc.

This work is licensed under the Creative Commons Attribution International License (CC BY).

http://creativecommons.org/licenses/by/4.0/

c) $\underset{\mathrm{EY}}{\mathrm{i}}$ Open Access

\begin{abstract}
Use of complementary and alternative medicine (CAM) in children with cancer is common and probably increasing. However data concerning use of CAM in siblings of children with an oncologic disease are missing so far. We conducted a population-based survey over a one-year period with 233 participants. Of the 209 respondents $(90 \%$ response rate) $20 \%$ reported CAM use from the time on when the sibling was diagnosed to have cancer, compared to a prevalence rate of $48 \%$ before cancer diagnosis. The most prevalent therapies were homeopathy, anthroposophic medicine and Bach flowers. The main reasons for use were to strengthen the immune system and to achieve physical stabilization. Socio-demographic factors associated with CAM use were higher parental education and higher family income. A majority of CAM users would recommend them. $66 \%$ of the users informed a physician about CAM use. No side effects were reported. Conclusions: There is a significant decrease in CAM use in siblings of pediatric cancer patients after ascertainment of
\end{abstract}

\footnotetext{
${ }^{*}$ Corresponding author.
}

How to cite this paper: Gottschling, S., et al. (2014) Use of Complementary and Alternative Medicine in Siblings of Pediatric Cancer Patients in Germany. A Population-Based Survey. Open Journal of Pediatrics, 4, 93-101. 
cancer in the affected sibling. Being out of the focus seems to be the main reason for non-use. Nevertheless the $20 \%$ CAM users rate CAM as very effective and would recommend CAM use to other parents.

\section{Keywords}

\section{Complementary Medicine; Cancer; Children; Siblings}

\section{Introduction}

\subsection{Background}

An increasing and generally high prevalence of complementary and alternative medicine (CAM) use has been documented worldwide in children with cancer [1]-[38]. Nevertheless determination of CAM use in pediatric populations is impeded by differences in definitions of CAM, by diverging methodology of the different studies, differences in the sociocultural background of the participants and by small sample sizes of the investigated populations [1] [8] [29] [39]. To the best of our knowledge, there is to date no published study focusing on changes in CAM use in siblings of pediatric cancer patients before and after cancer was diagnosed. There is one publication from the childhood cancer survivor study comparing CAM use of adult survivors of childhood cancer to CAM use of a sibling control reporting similar user rates between both groups of about $40 \%$ [26]. In contrast to our trial, the cancer diagnosis of the reported survivors dated back between 15 - 30 years.

\subsection{Definition}

CAM refers to a broad range of healing concepts, approaches and therapies that exist largely outside the institutions where conventional health care is taught and provided. It remains a considerable uncertainty about what exactly it is and which methods of treatment should be summarized under this term. The Cochrane Collaboration defines CAM as "a broad domain of healing resources that encompasses all health systems, modalities, practices and their accompanying theories and beliefs, other than those intrinsic to the politically dominant health system of a particular society or culture in a given historical period" [40]. CAM defined by the National Center of Complementary and Alternative Medicine (NCCAM) is "a group of diverse medical and health care systems, practices and products that are presently not considered to be part of conventional medicine” [40].

\subsection{Prevalence Studies}

While data concerning an increasing CAM use in adults with cancer is substantial [6], the use of CAM by children with malignancies is less well studied, but also appears to have a considerable relevance [1]. Prevalence rates of CAM use among pediatric oncology patients vary from $6 \%$ to 91\% [1]-[38]. CAM use in children with other chronic medical conditions varies from $1.8 \%$ to $84 \%$ [39] with the highest prevalence rates for neuropediatric patients [32] [39]. Prevalence rates for healthy children in Germany were reported to be about 53\% [32].

\subsection{Methodological Limitations of Published Studies}

Most studies are neither population based nor representative focusing on pediatric populations with specific diseases. Data about the CAM use of siblings of pediatric cancer patients in the context of a currently diagnosed malignancy are lacking.

\subsection{Aims}

We wanted to assess the prevalence and types of CAM therapies used as well as reasons for and against CAM utilisation in siblings of pediatric cancer patients. Moreover we were interested in socio-demographic factors, costs, perceived usefulness of the applied CAM, side effects and the issue whether CAM use was discussed with a physician. 


\section{Methods}

The survey was done in accordance with the local institutional review board, and the declaration of Helsinki. We conducted a questionnaire-based survey to examine the use of CAM in siblings of pediatric cancer patients in Germany. The survey was done from March 2004 to March 2005 at the rehabilitation clinic Katharinenhöhe, Germany. This specialized hospital in southern Germany covers about $40 \%$ of all children and adolescents with oncological diseases in Germany leading to a representative sample of German pediatric cancer patients and their siblings. The questionnaire used was based on the questionnaire used by our study group for different population-based surveys on pediatric cancer patients, healthy children and children with chronic medical conditions (with an extended part concerning socio-demographic data) [13] [14] [20] [21] [39]. It consisted of 50 items evaluating the following factors: Prevalence for CAM use before and after the sibling was diagnosed to have cancer, reasons for/against use, expectations towards CAM, financial expenditure including percentage of covering by insurance, source of recommendation, percentage of parents informing their physician about CAM utilization, applied CAM (a list of 69 CAM was provided together with the possibility of adding further CAM), observed adverse effects, perception of helpfulness, percentage of recommendation of CAM, socio-demographic aspects of users and non-users. The only exclusion criterion was insufficient knowledge of the German language. All participants received a questionnaire when admitted to the rehabilitation clinic Katharinenhöhe and were asked to drop them duly completed at the end of their stay in one of the sealed boxes positioned at the porter to assure anonymity. (The allotted questionnaires were then compared to the ones distributed to calculate the rate of return). Data were entered into an Access database (Microsoft). Statistical analysis was performed using the Statistical Package for Social Sciences (SPSS 19.0. SPSS Inc., Chicago, IL). Data are presented as mean (+/$\mathrm{SD})$. Means and standard deviations were calculated for continuous variables. For statistical comparison of continuous parameters, Student's t-test was employed. We used the Pearson chi-square test to compare differences between various groups regarding the use of CAM. A p-value $<0.05$ was considered significant.

\section{Results}

We received 209 analyzable out of 233 allotted questionnaires resulting in a return rate of 90\%. The study population consisted of 52\% male, with a mean age of 11.2 years (range 0.3 - 22.3 years). Table 1 outlines the prevalence of CAM use before and after cancer diagnosis in the sibling. The 167 CAM non-user were asked to give reasons for their decision not to use CAM. Reasons are detailed in Table 2.

Additional costs and perceived ineffectiveness of CAM were rarely stated (under 5\%). The 42 users were asked for their reasons concerning CAM use. Table 3 details the reasons for CAM use of 42 users.

\subsection{Expectations towards CAM}

Expectations of users towards CAM were high with $88 \%$ of the sibling's guardians being confident or even ab-

\begin{tabular}{cccc}
\hline Table 1. Prevalence rates of CAM use. & & \\
\hline Group/count & $\begin{array}{c}\text { Prevalence before } \\
\text { cancer diagnosis in the } \\
\text { sibling }\end{array}$ & $\begin{array}{c}\text { Prevalence after } \\
\text { cancer diagnosis in } \\
\text { the sibling }\end{array}$ & P-value \\
\hline $\begin{array}{c}\text { Siblings of pediatric } \\
\text { cancer patients (209) }\end{array}$ & $48 \%$ & $20 \%$ & $\mathrm{P}<0.001$ \\
\hline
\end{tabular}

Table 2. Reasons of non-users for non-appliance (multiple entries possible).

\begin{tabular}{lc}
\hline Reason & siblings \\
\hline lacking information about CAM & $37 \%$ \\
disadvice of the attending physician & $31 \%$ \\
fear of adverse effects & $21 \%$ \\
additional stress for the child & $16 \%$ \\
other reasons (not specified) & $16 \%$ \\
\hline
\end{tabular}


Table 3. Reasons for CAM use (multiple entries possible).

\begin{tabular}{lc}
\hline & siblings \\
\hline physical stabilisation & $29 \%$ \\
to strengthen the immune system & $24 \%$ \\
mental stabilisation & $21 \%$ \\
other reasons & $12 \%$ \\
detoxification & $5 \%$ \\
relaxation & $5 \%$ \\
\hline
\end{tabular}

solutely sure that CAM has beneficial effects.

\subsection{Financial Expenditure of CAM Use}

In most cases (82\%) less than 500€ was spent for CAM. In 7\% more than $2000 €$ was spent for CAM. $24 \%$ of all parents asked their health insurance company for coverage which was granted (full or partially) in $61 \%$ of the requests.

\subsection{Sources of Recommendation}

Parents received information about CAM mostly from their social environment (Table 4)

\subsection{How Many Users Discussed Their CAM Use with a Physician?}

The majority of all users (66\%) informed a physician about the CAM use of their child.

How were the reactions of the physicians towards the communicated CAM use? The majority of general practitioners (GP) 78\% and pediatricians 84\% was affirmative concerning CAM use. In 38\% CAM was prescribed by a GP or a pediatrician in private practice. Heilpraktiker prescribed $16 \%$ of CAM and $29 \%$ used self-medication.

\subsection{Applied CAM}

Homeopathy was the most often used CAM followed by anthroposophic medicine and Bach Flowers. Ranking of the different therapies related to the different groups are detailed in Table 5 .

\subsection{Adverse Effects}

Adverse effects of CAM use were not reported.

\subsection{Recommendation of CAM}

Parents were asked if they would recommend CAM use to other persons being in a comparable situation. The overwhelming majority (96\%) of CAM users would recommend certain CAM.

\subsection{Financial and Sociodemographic Aspects}

There was no significant difference in CAM use according to age, gender or religion.

Families with a low to medium income (up to $3000 €$ monthly) used CAM significantly lesser than families with a higher income $(\mathrm{P}=0.023)$. The same significance could be found concerning the educational level. The CAM use rate was significantly higher, if at least one parent had a tertiary education $(\mathrm{P}=0.012)$.

\section{Discussion}

The use of CAM within various diseases in children is of increasing interest within the last years. It is best studied for pediatric cancer patients with a reasonable number of published studies within the last two decades [1]-[38]. Most published studies were single-center studies with small numbers of participants focusing only on 
Table 4. Sources of recommendation about CAM (multiple entries possible).

\begin{tabular}{lc}
\hline Sources of information & siblings \\
\hline friends & $29 \%$ \\
attending physician & $17 \%$ \\
Heilpraktikers* & $14 \%$ \\
family & $12 \%$ \\
other physician & $10 \%$ \\
persons with related disease in the family & $10 \%$ \\
other sources & $7 \%$ \\
media & $5 \%$ \\
other health professionals & $2 \%$ \\
\hline
\end{tabular}

*A Heilpraktiker in Germany is a licenced healer without medical school education.

\section{Table 5. CAM ranking.}

\begin{tabular}{ll}
\hline & siblings \\
\hline 1. & homeopathy \\
2. & anthroposophic medicine \\
3. & Bach flowers \\
4. & massage \\
5. & phytotherapy \\
6. & vitamine preparations \\
7. & acupuncture \\
8. & balneotherapy \\
9. & dietary supplements \\
10. & bioresonance therapy \\
\hline
\end{tabular}

the affected patient. To the best of our knowledge our study is the first population-based study comparing CAM use in siblings of children with cancer before and after cancer was diagnosed. Another strength of our study is a questionnaire return rate of $90 \%$. In our trial we used the same questionnaire as in the population-based prevalence study published by our working group focusing on pediatric cancer patients, healthy children and children with chronic medical conditions in Germany [39].

\subsection{Prevalence}

Our results with a CAM use prevalence rate of $48 \%$ before cancer diagnosis is comparable to a rate we found in our population-based German survey in healthy children (53\%) [39]. It is also comparable to the recently published prevalence rate (36\%) reported in general pediatrics [32]. Mertens et al. reported about a $41 \%$ user rate in siblings of long-term childhood cancer survivors [26]. Interestingly CAM use rates decreased significantly after cancer diagnosis. We found that in a lesser extent also in children with cancer (45\% before down to $29 \%$ after cancer diagnosis), whereas the CAM user rates in adolescents with a malignancy slightly increased (from 33\% to $36 \%)$ [14].

\subsection{Used CAM}

Although a sample of 69 different CAM was given with an additional opportunity to add further therapies $68 \%$ of all used CAM were reflected by 10 different CAM. Homeopathy was the most often used CAM with 38\%, although no replicated large-scale trials with a rigorous design for any clinical disorder in children do exist [41]. Other popular CAM in our survey were anthroposophic medicine and Bach flowers. This range of popular CAM 
is in line with other European studies on CAM use [14] [21] [28] [39] whereas studies performed in the US or Canada report about spiritual healing, prayer and blessings being among the most prevalent CAM [2] [19] [25]. This reflects considerable socio-cultural differences between the investigated populations.

\subsection{Reasons for Use/Non-Use}

The main reasons for use were the intention to strengthen the immune system and to achieve physical and mental stabilization. These reasons are in line with other publications [8] [23] [39]. Reasons for declining CAM use were mainly a lack of information about CAM, disadvice of the attending physician and fear of adverse effects. Interestingly many parents used the "further comments" section. Reasons like "not necessary, child not sick" were among the most common remarks. We feel that siblings might fall out of the focus of parents to at least near- to intermediate term in the context of a newly diagnosed malignancy of an underage family member. This is even more evident when you compare our data to the publication of Mertens et al. [26] reporting an equivalent CAM use of long-term childhood cancer survivors and their siblings 15 to 30 years after cancer diagnosis.

\subsection{Socio-Demographic Factors}

While child's age, gender, religion and parental age were no significant predictors for CAM use, CAM use was associated with parental tertiary education and higher income. This supports the findings of other studies that a higher socioeconomic status is associated with CAM use [8] [14] [21] [35] [39].

\subsection{Costs}

Financial expenditure in most cases was low to moderate ( $<500 €$ in total). This corresponds to a low rate of non-users stating additional costs as a reason for not using CAM. In only 7\% of all CAM users more than 2000 $€$ in total was spent for CAM, which is low compared to their affected siblings ( $16 \%>2000 €)$ [14].

\subsection{Disclosure}

The majority of all users (66\%) spoke to a physician about CAM use. This is in contrast to the most published studies were the vast majority of the users did not inform their physician [1] [3] [12] [15] but in line with the data of our research group in different German populations [14] [21] [39]. This might reflect a change in the attitude of conventional health professionals towards CAM at least in Germany. We know from other studies that many physicians feel that they know to little about CAM to provide substantial advice often resulting in disapproval of CAM use in their patients [8] [42].

\subsection{Perceptions and Efficacy}

A total of $88 \%$ were confident that CAM had beneficial effects. This was also reflected by a very high rate of recommendations to other persons in a comparable situation. These positive perceptions of CAM are in line with other studies [1] [8] [14] [21] [30] [39] and might reflect the feeling of being empowered to take personal control of the child's condition. CAM is often perceived as natural, individualized, non-invasive and holistic; attributes rarely mentioned in context of conventional medicine [15]. In this regard it is particular dangerous that the vast majority perceives CAM as harmless. Most CAM users (77\%) are confident that interactions between CAM and conventional therapies are excluded [15]. Moreover many people (75\%) believe that CAM are tested concerning quality and adverse effects and are therefore safe [15].

\subsection{Safety}

We explicitly asked for possible adverse effects of CAM and further asked to specify them using a free-text field. In this study no single adverse event was reported.

\subsection{Limitations of This Study}

CAM use differs considerably depending on the socio-cultural context. Therefore studies on CAM will always be difficult to compare. Moreover the definitions of CAM are not standardized impeding comparisons between 
studies even more. For example it is controversial whether prayer and spiritual healing are CAM or not. We chose to offer a wide variety of CAM to make sure that we did not underestimate CAM use. The anonymous design of the study was another important factor to ensure compliance and reliable answers.

\section{Conclusion}

In summary, the CAM user rate among siblings of children with cancer in Germany is quite low compared to other pediatric subgroups (general paediatrics, healthy children, children with chronic medical conditions, children with cancer). This is demonstrated by a marked decline of CAM use after confirmed cancer diagnosis. The drop in the prevalence rates seems to represent an increase of parental attention towards the seriously ill child possibly drawing the attention away from the sibling. Nevertheless CAM use in children is common and therefore safety and efficacy of CAM especially of CAM with high prevalence rates should be studied in rigorous basic and clinical research.

\section{Acknowledgements}

The authors thank all the nurses and staff members of the University Children's Hospital Homburg and the rehabilitation clinic Katharinenhöhe especially Dr. Eberhard Leidig for their support. Parts of the study were supported by a Grant of the Elterninitiative krebskranker Kinder im Saarland e.V., Germany and Een Häerz fir kriibskrank Kanner asbl, Luxembourg. All authors state that no potential conflict of interest is involved with this work.

\section{References}

[1] Bishop, F.L., Prescott, P., Chan, Y.K., Saville, J., von Elm, E. and Lewith, G.T. (2010) Prevalence of Complementary Medicine Use in Pediatric Cancer: A Systematic Review. Pediatrics, 125, 768-776. http://dx.doi.org/10.1542/peds.2009-1775

[2] Bold, J. and Leis, A. (2001) Unconventional Therapy Use among Children with Cancer in Saskatchewan. Journal of Pediatric Oncology Nursing, 18, 16-25. http://dx.doi.org/10.1053/jpon.2001.20403

[3] Clerici, C.A., Veneroni, L., Giacon, B., Mariani, L. and Fossati-Bellani, F. (2009) Complementary and Alternative Medical Therapies Used by Children with Cancer Treated at an Italian Pediatric Oncology Unit. Pediatric Blood \& Cancer, 53, 599-604. http://dx.doi.org/10.1002/pbc.22093

[4] Cohen, M.H., Kemper, K.J., Stevens, L., Hashimoto, D. and Gilmour, J. (2005) Pediatric Use of Complementary Therapies: Ethical and Policy Choices. Pediatrics, 116, e568-75. http://dx.doi.org/10.1542/peds.2005-0496

[5] Davis, M.P. and Darden, P.M. (2003) Use of Complementary and Alternative Medicine by Children in the United States. Archives of Pediatrics \& Adolescent Medicine, 157, 393-396. http://dx.doi.org/10.1001/archpedi.157.4.393

[6] Eisenberg, D.M., Kessler, R.C., Foster, C., Norlock, F.E., Calkins, D.R. and Delbanco, T.L. (1993) Unconventional Medicine in the United States. Prevalence, Costs, and Patterns of Use. New England Journal of Medicine, 328, 246-252. http://dx.doi.org/10.1056/NEJM199301283280406

[7] Ernst, E. (1999) Prevalence of Complementary/Alternative Medicine for Children: A Systematic Review. European Journal of Pediatrics, 158, 7-11. http://dx.doi.org/10.1007/s004310051000

[8] Ernst, E. and Cassileth, B.R. (1998) The Prevalence of Complementary/Alternative Medicine in Cancer: A Systematic Review. Cancer, 83, 777-782. http://dx.doi.org/10.1002/(SICI)1097-0142(19980815)83:4<777::AID-CNCR22>3.0.CO;2-O

[9] Faw, C., Ballentine, R., Ballentine, L. and vanEys, J. (1977) Unproved Cancer Remedies. A Survey of Use in Pediatric Outpatients. JAMA, 238, 1536-1538. http://dx.doi.org/10.1001/jama.1977.03280150106041

[10] Fernandez, C.V., Stutzer, C.A., MacWilliam, L. and Fryer, C. (1998) Alternative and Complementary Therapy Use in Pediatric Oncology Patients in British Columbia: Prevalence and Reasons for Use and Nonuse. Journal of Clinical Oncology, 16, 1279-1286.

[11] Genc, R.E., Senol, S., Turgay, A.S. and Kantar, M. (2009) Complementary and Alternative Medicine Used by Pediatric Patients with Cancer in Western Turkey. Oncology Nursing Forum, 36, E159-164. http://dx.doi.org/10.1188/09.ONF.E159-E164

[12] Gomez-Martinez, R., Tlacuilo-Parra, A. and Garibaldi-Covarrubias, R. (2007) Use of Complementary and Alternative Medicine in Children with Cancer in Occidental, Mexico. Pediatric Blood \& Cancer, 49, 820-823.

http://dx.doi.org/10.1002/pbc.21101 
[13] Gottschling, S., Langler, A., Tautz, C. and Graf, N. (2006) Complementary and Alternative Medicine in Pediatric Oncology. Klinische Pädiatrie, 218, 157-164. http://dx.doi.org/10.1055/s-2006-933400

[14] Gottschling, S., Meyer, S., Längler, A., Scharifi, G., Ebinger, F. and Gronwald, B. (2014) Differences in Use of Complementary and Alternative Medicine between Children and Adolescents with Cancer in Germany. A Population Based Survey. Pediatric Blood \& Cancer, 61, 488-492. http://dx.doi.org/10.1002/pbc.24769

[15] Gözüm, S., Arikan, D. and Büyükavci, M. (2007) Complementary and Alternative Medicine Use in Pediatric Oncology Patients in Eastern Turkey. Cancer Nursing, 30, 38-44. http://dx.doi.org/10.1097/00002820-200701000-00007

[16] Hamidah, A., Rustam, Z.A., Tamil, A.M., Zarina, L.A., Zulkifli, Z.S. and Jamal, R. (2009) Prevalence and Parental Perceptions of Complementary and Alternative Medicine Use by Children with Cancer in a Multi-Ethnic Southeast Asian Population. Pediatric Blood \& Cancer, 52, 70-74. http://dx.doi.org/10.1002/pbc.21798

[17] Karali, Y., Demirkaya, M. and Sevinir, B. (2012) Use of Complementary and Alternative Medicine in Children with Cancer: Effect on Survival. Pediatric Hematology-Oncology, 29, 335-344. http://dx.doi.org/10.3109/08880018.2012.670368

[18] Kelly, K.M. (2007) Complementary and Alternative Medicines for Use in Supportive Care in Pediatric Cancer. Support Care Cancer, 15, 457-460. http://dx.doi.org/10.1007/s00520-006-0162-2

[19] Kelly, K.M., Jacobson, J.S., Kennedy, D.D., Braudt, S.M., Mallick, M. And Weiner, M.A. (2000) Use of Unconventional Therapies by Children with Cancer at an Urban Medical Center. Journal of Pediatric Hematology/Oncology, 22, 412-416. http://dx.doi.org/10.1097/00043426-200009000-00005

[20] Längler, A., Spix, C., Gottschling, S., Graf, N. and Kaatsch, P. (2005) Elternbefragung zur Anwendung Alternativer und Komplementärer Behandlungsmethoden in der Kinderonkologie in Deutschland. Klinische Pädiatrie, 217, 357364. http://dx.doi.org/10.1055/s-2005-872522

[21] Laengler, A., Spix, C., Seifert, G., Gottschling, S., Graf, N. and Kaatsch, P. (2008) Complementary and Alternative Treatment Methods in Children with Cancer: A Population-Based Retrospective Survey on the Prevalence of Use in Germany. European Journal of Cancer, 44, 2233-2240. http://dx.doi.org/10.1016/j.ejca.2008.07.020

[22] Lim, J., Wong, M., Chan, M.Y., Tan, A.M., Rajalingam, V., Lim, L.P., Lou, J. and Tan, C.L. (2006) Use of Complementary and Alternative Medicine in Paediatric Oncology Patients in Singapore. Annals Academy of Medicine Singapore, 35, 753-758.

[23] Madsen, H., Andersen, S., Nielsen, R.G., Dolmer, B.S., Høst, A. and Damkier, A. (2003) Use of complementary/alternative medicine among paediatric patients. European Journal of Pediatrics, 162, 334-341.

[24] Martel, D., Bussières, J.F., Théorêt, Y., Lebel, D., Kish, S., Moghrabi, A. and Laurier, C. (2005) Use of Alternative and Complementary Therapies in Children with Cancer. Pediatric Blood \& Cancer, 44, 660-668. http://dx.doi.org/10.1002/pbc.20205

[25] McCurdy, E.A., Spangler, J.G., Wofford, M.M., Chauvenet, A.R. and McLean, T.W. (2003) Religiosity Is Associated with the Use of Complementary Medical Therapies by Pediatric Oncology Patients. Journal of Pediatric Hematology/Oncology, 25, 125-129. http://dx.doi.org/10.1097/00043426-200302000-00008

[26] Mertens, A.C., Sencer, S., Myers, C.D., Recklitis, C., Kadan-Lottick, N., Whitton, J., Marina, N., Robison, L.L. and Zeltzer, L. (2008) Complementary and Alternative Therapy Use in Adult Survivors of Childhood Cancer: A Report from the Childhood Cancer Survivor Study. Pediatric Blood \& Cancer, 50, 90-97. http://dx.doi.org/10.1002/pbc.21177

[27] Molassiotis, A. and Cubbin, D. (2004) Thinking outside the Box: Complementary and Alternative Therapies Use in Paediatric Oncology Patients. European Journal of Oncology Nursing, 8, 50-60. http://dx.doi.org/10.1016/S1462-3889(03)00054-1

[28] Mottonen, M. and Uhari, M. (1997) Use of Micronutrients and Alternative Drugs by Children with Acute Lymphoblastic Leukemia. Medical and Pediatric Oncology, 28, 205-208. http://dx.doi.org/10.1002/(SICI)1096-911X(199703)28:3<205::AID-MPO10>3.0.CO;2-D

[29] Ndao, D.H., Ladas, E.J., Bao, Y., Cheng, B., Nees, S.N., Levine, J.M. and Kelly, K.M. (2013) Use of Complementary and Alternative Medicine among Children, Adolescent, and Young Adult Cancer Survivors: A Survey Study. Journal of Pediatric Hematology/Oncology, 35, 281-288. http://dx.doi.org/10.1097/MPH.0b013e318290c5d6

[30] Paisley, M.A., Kang, T.I., Insogna, I.G. and Rheingold, S.R. (2011) Complementary and Alternative Therapy Use in Pediatric Oncology Patients with Failure of Frontline Chemotherapy. Pediatric Blood \& Cancer, 56, 1088-1091. http://dx.doi.org/10.1002/pbc.22939

[31] Pendergrass, T.W. and Davis, S. (1981) Knowledge and Use of “Alternative” Cancer Therapies in Children. The American journal of pediatric hematology/oncology, 3, 339-345.

[32] Post-White, J., Fitzgerald, M., Hageness, S. and Sencer, S.F. (2009) Complementary and Alternative Medicine Use in Children with Cancer and General and Specialty Pediatrics. Journal of Pediatric Oncology Nursing, 26, 7-15. http://dx.doi.org/10.1177/1043454208323914 
[33] Sawyer, M.G., Gannoni, A.F., Toogood, I.R., Antoniou, G. and Rice, M. (1994) The Use of Alternative Therapies by Children with Cancer. Medical Journal of Australia, 160, 320-322.

[34] Singendonk, M., Kaspers, G.J., Naafs-Wilstra, M., Meeteren, A.S., Loeffen, J. and Vlieger, A. (2013) High Prevalence of Complementary and Alternative Medicine Use in the Dutch Pediatric Oncology Population: A Multicenter Survey. European Journal of Pediatrics, 172, 31-37. http://dx.doi.org/10.1007/s00431-012-1821-6

[35] Spigelblatt, L., Laîné-Ammara, G., Pless, I.B. and Guyver, A. (1994) The Use of Alternative Medicine by Children. Pediatrics, 94, 811-814.

[36] Tomlinson, D., Hesser, T., Ethier, M.C. and Sung, L. (2011) Complementary and Alternative Medicine Use in Pediatric Cancer Reported during Palliative Phase of Disease. Support Care Cancer, 19, 1857-1863. http://dx.doi.org/10.1007/s00520-010-1029-0

[37] Weyl Ben Arush, M., Geva, H., Ofir, R., Mashiach, T., Uziel, R. and Dashkovsky, Z. (2006) Prevalence and Characteristics of Complementary Medicine Used by Pediatric Cancer Patients in a Mixed Western and Middle-Eastern Population. Journal of Pediatric Hematology/Oncology, 28, 141-146. http://dx.doi.org/10.1097/01.mph.0000210404.74427.10

[38] Yeh, C.H., Tsai, J.L., Li, W., Chen, H.M., Lee, S.C., Lin, C.F. and Yang, C.P. (2000) Use of Alternative Therapy among Pediatric Oncology Patients in Taiwan. Pediatric Hematology-Oncology, 17, 55-65. http://dx.doi.org/10.1080/088800100276668

[39] Gottschling, S., Gronwald, B., Schmitt, S., Schmitt, C., Längler, A., Leidig, E., Meyer, S., Baan, A., Shamdeen, M.G., Berrang, J. and Graf, N. (2013) Use of Complementary and Alternative Medicine in Healthy Children and Children with Chronic Medical Conditions in Germany. Complementary Therapies in Medicine, 21, S61-69. http://dx.doi.org/10.1016/j.ctim.2011.06.001

[40] http://nccam.nih.gov/health/whatiscam

[41] Altunc, U., Pittler, M.H. and Ernst, E. (2007) Homeopathy for Childhood and Adolescence Ailments: Systematic Review of Randomized Clinical Trials. Mayo Clinic Proceedings, 82, 69-75.

[42] Längler, A., Boeker, R., Kameda, G., Seifert, G., Edelhäuser, F. and Ostermann, T. (2013) Attitudes and Beliefs of Paediatric Oncologists Regarding Complementary and Alternative Therapies. Complementary Therapies in Medicine, 21, S10-19 http://dx.doi.org/10.1016/j.ctim.2012.02.006 